https://helda.helsinki.fi

\title{
Frequent consumption of sugar-sweetened beverages and sweets starts at early age
}

\section{Laitala, Marja-Liisa}

2018-03

Laitala , M-L , Vehkalahti , M M \& Virtanen , J I 2018 , ' Frequent consumption of sugar-sweetened beverages and sweets starts at early age ' , Acta Odontologica Scandinavica , vol. 76 , no. 2 , pp. 105-110 . https://doi.org/10.1080/00016357.2017.1387929

http://hdl.handle.net/10138/310308

https://doi.org/10.1080/00016357.2017.1387929

unspecified

acceptedVersion

Downloaded from Helda, University of Helsinki institutional repository.

This is an electronic reprint of the original article.

This reprint may differ from the original in pagination and typographic detail.

Please cite the original version. 
Frequent Consumption of Sugar-Sweetened Beverages and Sweets Starts at Early Age

Laitala M-L ${ }^{1,2}$, Vehkalahti MM ${ }^{3}$, Virtanen JI ${ }^{1,4}$.

Laitala Marja-Liisa, ${ }^{1}$ Research Unit of Oral Health Sciences, Faculty of Medicine, University of Oulu, Finland and ${ }^{2}$ Kallio Public Health Care, Ylivieska, Finland. Postal address: P.O.Box 5000, FI-90014 University of Oulu, Finland, tel. +358406786785, e-mail: marja-liisa.laitala@oulu.fi ORCID ID: 0000-0001-7323-9862

Vehkalahti Miira M, ${ }^{3}$ Department of Oral and Maxillofacial Diseases, Faculty of Medicine, University of Helsinki, Helsinki, Finland. Postal address: P.O.Box 41, FI-00014 University of Helsinki, Finland, tel. +358504151305, e-mail: miira.vehkalahti@ helsinki.fi ORCID ID: 0000$0002-6319-854 X$

Virtanen Jorma I, ${ }^{1}$ Research Unit of Oral Health Sciences, Faculty of Medicine, University of Oulu, Finland and ${ }^{4}$ Medical Research Center, Oulu University Hospital, Oulu, Finland. Postal address: P.O.Box 5000, FI-90014 University of Oulu, Finland, tel. +358294485584, e-mail: jorma.virtanen@oulu.fi

Correspondence:

Dr Marja-Liisa Laitala, marja-liisa.laitala@oulu.fi,_Tel. +358 40 6786785, Fax: +358 85375560

Key words: child, oral health, sugar-sweetened beverages, sweets 


\begin{abstract}
Objectives: We aimed to investigate the habitual consumption of sugar-sweetened beverages (SSBs) and sweets in relation to mothers' behaviours and practices with their infants.

Methods: We targeted mothers with children 1 to 24 months $(\mathrm{N}=200)$ visiting Public Child Health clinics in Finland. During routine visits mothers $(\mathrm{N}=179)$ volunteered to complete a selfadministered anonymous questionnaire about their child's health-related behaviours (consumption of sweets and SSBs, tooth brushing frequency). The questionnaires also included questions about the mothers' background (age, education) and health-related behaviours (consumption of sweets, tooth brushing frequency, smoking habits). The children were categorised by age, and Chi-squared tests, Fischer's exact test, ANOVA, and correlation coefficient served for the statistical analyses. Results: Of those under six months, almost half (44\%) received SSBs, and $45 \%$ of them more than once a week. Their use gradually increased by age such that by 19-24 months, all received SSBs at least sometimes, and 56\%, frequently. Fewer than half of the mothers (33-43\%) gave sweets to their children between the ages of $10-15$ months, but $92 \%$ by the age of two years. Children's twice-a-day tooth brushing increased from $14 \%$ to $33 \%$. The child's age and tooth brushing frequency correlated with the consumption of sucrose-sweetened products $(\mathrm{r}=0.458)$.

Conclusions: Infants frequent consumption of sugar-sweetened products begins early in childhood. Thus, tackling these common risk factors in the first years of life is essential and calls for healthpromoting actions in multiple areas that target primarily the parents of infants.
\end{abstract}




\section{Introduction}

Though highly preventable, dental caries remains among the most common health care resourceintensive infectious diseases in children [1-3]. Ample evidence shows the role of diet and added sugar in the manifestation and progression of dental caries [4,5]; among these factors are the frequent use of sugar-sweetened beverages (SSBs) and sweets [6,7]. These behavioral risk factors cause not only dental caries, but many general diseases (e.g. cardiovascular diseases (CVD), diabetes and obesity) share these same risk factors, which are becoming a major public health concern worldwide $[8,9]$. These risk factors highlight the need for healthy lifestyles early in life, from infancy to childhood, in an effort to curb common health risks.

The consumption of added sugar has increased dramatically over the past three decades: average global consumption has grown $46 \%$ from 48 to 70 grams per day [10]. The current intake of added sugars in both developed and developing countries is markedly higher than the WHO's recommendation of less than $10 \%$ of daily total energy [11]. In the USA, for instance, sweetened beverages use $31 \%$ of the sugar supply [10]. SSB consumption is associated with adverse health outcomes, including child obesity [12]. The impact of parents and parental feeding practices (formula feeding, the early introduction of solids, using food as a reward, pressure to eat, perceived barriers) are important factors contributing to SSB consumption in children [12]. For instance, the annual consumption of SSBs in Finland since the 1990s has risen from 45 to 56 liters per person [13].

In Finland, as in the other the Nordic countries, health and welfare services for children and families are mainly arranged by public sector and financed by taxes [14]. As part of public health care, maternity and child health clinics have since the 1920s provided free-of-charge services to 
pregnant mothers and children under school age. These services include general health check-ups, vaccinations, and personal counselling, and virtually all families use these free-of-charge services [15]. During the first year of life, children visit the clinic nearly every month, after which they are scheduled for an average of three visits annually. These services also include oral health care. Oral health education is available to parent groups in antenatal classes and as detailed instructions at individual appointments both during and after childbirth up to school age [15].

To optimize the timing of health promotion, it is necessary to find out the dietary habits in the families. The evidence of the consumption of sugar-sweetened products of Finnish infants is scarce. We aimed to investigate the consumption of sugar-sweetened beverages and sweets in relation to mothers' behaviors and practices with their infants up to 24 months of age.

\section{Material and methods}

As part of the study targeting mothers with children attending public child health clinics in Southern Finland [16], the present study included those mothers with children between the ages of 1 and 24 months $(\mathrm{N}=200)$ and investigated questions about the child's health-related behaviors. Altogether 179 mothers to single children (no twins) answered all questions, thus the number of children and mothers were equal. We excluded 21 non-responders (mothers whose questionnaires had missing answers concerning consumption of sugar sweetened products). The study population comprised mothers with children attending two municipal child health clinics in two medium-sized towns (<50,000 inhabitants) with similar socio-economic and ethnic backgrounds; main source of livelihood in the towns being service trade and industry. We estimated a four- to six-month period to obtain a representative sample of mothers from these health clinics. The Human Sciences Ethics 
Committee of the University of Oulu approved the study ( $\mathrm{Nr}$ 2/2/2013). A detailed description of the survey has been presented earlier by Virtanen et al. [16].

During their routine visits to these Public Child Health clinics, mothers were invited to voluntarily complete a self-administered anonymous questionnaire distributed by the health nurses in charge and returned immediately after the mothers had completed them. Questions about the child's health-related behaviors included frequencies of tooth brushing and the consumption of sugarsweetened beverages (such as home-made or commercial juices, fizzy drinks, hot chocolate etc.) and sweets (sugar containing lozenges and candies, chocolate products etc.) with six answer options (the corresponding scores appear in brackets): Never (0), seldom (1), once a week (2), every other day (3), once a day (4), more than once a day (5). For the analyses, we categorized these responses regarding consumption of sugar-sweetened beverages as never/less than weekly/once a week/more frequently, and consumption of sweets as yes/no. For further analyses, the original scores on the consumption of SSBs and sweets, ranging from 0 to 5 , were summed up to describe the intensity of consumption of sugar-sweetened products. The theoretical range of these intensity scores was from 0 to 10 . The greater the scores the more frequent was the total use of sucrose-sweetened products.

The child's age was expressed in months; the mean age of the children was 10.8 months (SD 7.0), median 10 months. In the analyses, age was later categorized into six groups based on the guidelines of the Ministry of Social Affairs and Health (2004) as follows: < 6 months (infants begin to eat solid food), 6-9 months (first deciduous teeth erupt), 10-12 months (child begins to eat the same food as his or her family), 13-15 months (end of maternity leave and changes in diet), 1618 months (first deciduous molars erupt) / 19-24 months. 
Questions about the mothers' background and behaviors included level of education attained, with three answer options: Basic (only nine years of compulsory education), middle (vocational or technical training), or higher (polytechnic or academic) education. The age of the mothers was grouped into five categories: $<25,25-29,30-34,35-39$, and 40+; the last two categories were later combined into 35+. Questions about smoking habits had three answer options: Yes, regularly; yes, occasionally; and never. Questions about tooth brushing had four answer options: Almost every day, once a day, more than once a day, and never. For the question about their own consumption of sweets, the mothers had three options from which to choose: No more than once a week, two to three times a week, and more frequently. A description of the mothers' characteristics appears in Table 1.

Statistical evaluation included Chi-squared tests for differences between the age groups in frequencies of tooth brushing as well as consumption of sweets and SSBs with Fischer's exact test applied when needed and ANOVA for assessing differences in the mean values. Box-and-plot graphs described the distributions of the intensity scores. Pearson's correlation coefficient (r) measured the strength of associations between the intensity score and selected variables. Fisher's transformation was applied to test $\mathrm{r} \neq 0$.

\section{Results}

The consumption of sugar-sweetened products began in early infancy. In the youngest age group ( $<6$ months), almost half of the infants (44\%) received SSBs, and for $45 \%$ of them, more than once a week. The consumption of SSBs was more common among children over one year of age than among those under that age (Table 2). All children in the oldest age group (19-24 months) received SSBs at least sometimes, and 56\% of these children more than once a week. Less than 
half of the mothers with children aged 10-12 and 13-15 months, but almost every mother with children aged 16 months and older, reported giving sweets to their children. All of the mothers with children aged one year and older reported brushing their children's teeth, two thirds of them daily. The proportions of at least twice daily brushers varied by age group from 14\% (children aged $<6$ months) to $33 \%$ (children aged 16-18 months) (Table 2).

Figure 1 illustrates the differences by age group in the frequencies of consumption of sugarsweetened products and of twice-daily tooth brushing. By the age of 10-12 months, the consumption of both sweets and SSBs began to increase markedly while the frequency of twicedaily tooth brushing remained almost at the same level.

The sum score for the intensity of consumption of sugar-sweetened products ranged from 0 to 6 and was greater the older the child: up to 12 months of age, the mean was around one; among 13to 15-month-olds, 2.4 ( $\mathrm{SD}=1.3$ ); among 16- to 18-month-olds, 2.7 ( $\mathrm{SD}=1.6$ ); and among 19- to 24-month-olds, 3.7 ( $\mathrm{SD}=1.4)$, with statistically significant $(\mathrm{p}<0.001)$ differences by age. The distributions of these intensity scores were wide in each age group, as the box-and-plot graphs show (Figure 2). Half of the mothers reported giving no sugar-sweetened products to their children up to the age of 12 months (median score $=0$ ); after that age, the median was around two among 13- to 18-month-olds, and over four among 19- to 24-month-olds.

Analysis with correlation coefficients identified the age of the child and the child's tooth brushing frequency as the strongest factors associated with the consumption of sugar-sweetened products, both with $r=0.458(\mathrm{p}<0.001)$. Further, the child's age and tooth brushing frequency were strongly associated $(\mathrm{r}=0.404 ; \mathrm{p}<0.001)$. The mother's characteristics showed weak correlations with the child's consumption of sugar-sweetened products: age $(r=0.132 ; p=0.039)$, level of education $(r$ 
$=0.024 ; \mathrm{p}=0.375)$, tooth brushing frequency $(\mathrm{r}=-0.126 ; \mathrm{p}=0.046)$, smoking habit $(\mathrm{r}=-0.115$; $\mathrm{p}=0.062)$, and consumption of sweets $(\mathrm{r}=-0.120 ; \mathrm{p}=0.055)$.

\section{Discussion}

Habitual consumption of sugar-sweetened products among Finnish children seems to begin early. At least half of the mothers gave sugar-sweetened beverages to their children on a weekly basis from the age of 13 months, and almost all gave them sweets from the age of 16 months. Unexpectedly, mothers' health-related behaviors correlated weakly with their practices towards their children, as favorable habits associated with both the child's frequent or, sometimes, infrequent consumption of sugar-sweetened products. Contrary to the results of a previous study, which found that parents with higher levels of education typically gave fewer sugar-sweetened products to their children [17], mothers' education level did not show strong correlation with child's health-related behaviors. The knowledge of Finnish mothers on oral health-related behaviors has been reported to be good [18]. Rather than lack of knowledge, the reason for unfavorable habits among the Finnish mothers seems to be their attitudes; although the mothers are well aware of the unhealthiness of sugar-sweetened products, they nevertheless give them to their children.

Child's flavor-related experiences begin already in utero and continue through breastfeeding [19]. In addition, infants who received SSBs during the first six months of life maintain their desire for sweet flavors [20]. However, reports on whether exposure to sweet flavors early in life increases one's acceptance of sweet tastes later in life are not unequivocal [21]. Mothers of young children may believe that sugar is part of a "normal" diet, which may lead to their children growing accustomed to sweet flavors already in infancy. Such thinking increases not only one's risk for 
dental caries, but also child's risk for obesity and other general health disorders [6,22,23]. Dietary habits established in childhood typically remain constant throughout adulthood [24,25], and mothers often transmit their oral health-related habits to their children [26,27]. It is therefore important to advise families with young children to adopt and maintain healthy practices, and to follow feeding recommendations, as well as to support families' efforts to improve their healthrelated behaviors, and thus to help their children maintain their health throughout adolescence and until adulthood - and not just good oral, but also good general health.

Our results are in line with the findings of Slade et al. [28], who reported that $32 \%$ of infants younger than six months drank SSBs regularly. Leermakers et al. [29] recently showed that the heavy consumption of SSBs begins in infancy. Children with the highest intakes of SSBs are more likely to be overweight or obese than children with lower intakes of such drinks [12,30,31]. Consequently, higher intakes of SSBs in childhood lead to increased risk for CVD in adulthood [32-34]. Moreover, the WHO recommends limiting sugar consumption among infants and young children by, for instance, regulating the marketing of sugar-sweetened beverages and foods [35].

To our knowledge, this is the first study to report on the consumption of SSBs among Finnish infants. The participation rate in maternity and child health clinics in Finland has been reported to be nearly $100 \%$ [36]. Our study was conducted in two typical Finnish towns with similar socioeconomic features and population structure [16]. The results drawn from this study population, which featured a convenience sample from two health clinics in Southern Finland, do not necessarily stand for the circumstances of Finnish mothers with small children in general. However, regional differences regarding indicators for health and welfare of children in Finland are relatively minor [37]. The questionnaire has been used in earlier studies, but it has not been validated. This can be considered as a limitation of the study. Another limitation may be a tendency 
to provide favorable responses, also known as social desirability [38], especially seen among females [39], which could have influenced the responses of the mothers when reporting their health-related habits in the survey. Here, the mothers completed the questionnaires anonymously, and the effect of social desirability might not be as high as e.g. in face-to-face interviews [40]. However, the children's consumption of sugar-sweetened products can be even higher than reported. Similarly, mothers may have overestimated the frequency of tooth brushing. This could be true especially among the mothers of children younger than 6 months who reported brushing at least once a day. These perceptions make our results even more worrying. We did not ask about the financial incomes of the families, however the education level attained we used has been shown to be a good proxy indicator for socio-economic status of the families $[27,41]$.

Contrary to earlier assumptions the associations between children's consumption of sucrosesweetened products and mothers' behaviors were weak, thus calling for further research in the field. Our results, even though including limited number of participants, suggest that for many infants, the frequent consumption of sugar-sweetened products begins in early childhood. Thus, tackling these common risk factors in the first years of life is essential and calls for healthpromoting actions in multiple areas that target the parents of infants. This places responsibilities on health care providers, industry, communities, governments, and the media. To effectively promote health in children, we must better understand the determinants that influence the healthrelated behavior of mothers of infants.

\section{Disclosure of interest}

The authors declare no conflict of interest. 


\section{References}

1. Bagramian RA, Garcia-Godoy F, Volpe AR. The global increase in dental caries. A pending public health crisis. Am J Dent. 2009;22(1):3-8.

2. Do LG. Distribution of caries in children: variations between and within populations. J Dent Res. 2012;91(6):536-543.

3. Kassebaum NJ, Bernabé E, Dahiya M, et al. Global burden of untreated caries: a systematic review and metaregression. J Dent Res. 2015;94(5):650-658.

4. Li Y. Controlling sugar consumption still has a role to play in the prevention of dental caries. J Evid Based Dent Pract. 2011;11(1):24-26.

5. Moynihan PJ, Kelly SA. Effect on caries of restricting sugars intake: systematic review to inform WHO guidelines. J Dent Res. 2014;93(1):8-18.

6. Brown CL, Halvorson EE, Cohen GM, et al. Addressing childhood obesity: opportunities for prevention. Pediatr Clin North Am. 2015;62(5):1241-1261.

7. de Koning L, Malik VS, Kellogg MD, et al. Sweetened beverage consumption, incident coronary heart disease, and biomarkers of risk in men. Circulation. 2012;25(14):1735-741.

8. Malik VS, Pan A, Willett WC, et al. Sugar-sweetened beverages and weight gain in children and adults: a systematic review and meta-analysis. Am J Clin Nutr. 2013;98(4):1084-1102.

9. Sheiham A. The role of the dental team in promoting dental health and general health through oral health. Int Dent J. 1992;42(4):223-228.

10. Credit Suisse Research Institute. Sugar consumption at crossroads; 2013 [cited 2017 September 4]. Available from: http://wphna.org/wp-content/uploads/2014/01/139_Credit_Suisse_Sugar_crossroads.pdf

11. World Health Organization. WHO calls on countries to reduce sugars intake among adults and children; 2015 [cited 2017 September 4]. Available from: http://www.who.int/mediacentre/news/releases/2015/sugar-guideline/en/

12. Mazarello Paes V, Hesketh K, O'Malley C, et al. Determinants of sugar-sweetened beverage consumption in young children: a systematic review. Obes Rev. 2015;16(11):903-913. 
13. The Finnish Food and Drink Industries' Federation; 2015 [cited 2017 September 4]. Available from: http://www.etl.fi/media/aineistot/tilastot/tietohaarukka2015_suomi.pdf (in Finnish).

14. Vuorenkoski L, Mladovsky P, Mossialos E. Finland: Health system review. Health Systems in transition. 2008;10(4):1-168.

15. Ministry of Social Affairs and Health, Finland. Child health clinics in support of families with children. Guidelines for local authorities on arranging the work of the clinics. Helsinki 2004. [cited 2017 September 4]. Available from: http://stm.fi/documents/1271139/1447712/Julkaisuja_2004_13.pdf/c26b6115-71f0-4a18a8b9-2cb8cb65dc2a

16. Virtanen JI, Vehkalahti KI, Vehkalahti MM. Oral health behaviors and bacterial transmission from mother to child: an explorative study. BMC Oral Health. 2015;15:75 doi:10.1186/s12903-015-0051-5

17. Astrøm AN, Kiwanuka SN. Examining intention to control preschool children's sugar snacking: a study of carers in Uganda. Int J of Paed Dent. 2006;16(1):10-18.

18. Laitala M-L, Toivonen J, Välitorppa H, et al. Knowledge, attitudes and behavior related to oral health among mothers with young children. J Nurs Sci. 2017;29(1):3-12.

19. Mennella JA, Nicklaus S, Jagolino AL, et al. Variety is the spice of life: strategies for promoting fruit and vegetable acceptance during infancy. Physiol Behav. 2008;94(1):29_ 38.

20. Beauchamp GK, Moran M. Dietary experience and sweet taste preference in human infants. Appetite. 1982;3(2):139-152.

21. Nehring I, Kostka T, von Kries R, et al. Impacts of in utero and early infant taste experiences on later taste acceptance: a systematic review. J Nutr. 2015;145(6):1271-1279.

22. Hayden C, Bowler JO, Chambers S, et al. Obesity and dental caries in children: a systematic review and meta-analysis. Community Dent Oral Epidemiol. 2013;41(4):289_ 308.

23. Hu FB. Resolved: there is sufficient scientific evidence that decreasing sugar-sweetened beverage consumption will reduce the prevalence of obesity and obesity-related diseases. Obes Rev. 2013;14(8):606-619. 
24. Lake AA, Rugg-Gunn AJ, Hyland RM, et al. Longitudinal dietary change from adolescence to adulthood. Perceptions, attributions and evidence. Appetite 2004;42(3):255-263.

25. Liem DG, Mennella JA. Sweet and sour preferences during childhood: role of early experiences. Dev Psychobiol. 2002;41(4):388-395.

26. Mattila ML, Rautava P, Ojanlatva A, et al. Will the role of family influence dental caries among seven-year-old children? Acta Odont Scand. 2005;63(2):73-84.

27. Poutanen R, Lahti S, Tolvanen M, et al. Parental influence on children's oral health-related behavior. Acta Odont Scand. 2006;64(5):286-292.

28. Slade GD, Sanders AE, Bill CJ, et al. Risk factors for dental caries in the five-year-old South Australian population. Aust Dent J. 2006;51(2):130-139.

29. Leermakers ET, Felix JF, Erler NS, et al. Sugar-containing beverage intake in toddlers and body composition up to age 6 years: the Generation R study. Eur J Clin Nutr. 2015;69(3):314-321.

30. Park S, Pan L, Sherry B, Li R. The association of sugar-sweetened beverage intake during infancy with sugar-sweetened beverage intake at 6 years of age. Pediatrics. 2014;134 Suppl $1:$ S56-62.

31. Seo DC, King MH, Kim N, et al. Predictors for persistent overweight, deteriorated weight status, and improved weight status during 18 months in a school-based longitudinal cohort. Am J Health Promot. 2015;30(1):22-27.

32. Nadeau KJ, Maahs DM, Daniels SR, et al. Childhood obesity and cardiovascular disease: links and prevention strategies. Nat Rev Cardiol. 2011;8(9):513-525.

33. Rahman I, Wolk A, Larsson SC. The relationship between sweetened beverage consumption and risk of heart failure in men. Heart. 2015;101(24):1961-1965.

34. Ruff RR. Sugar-sweetened beverage consumption is linked to global adult morbidity and mortality through diabetes mellitus, cardiovascular disease and adiposity-related cancers. Evid Based Med. 2015;20(6):223-224.

35. WHO. Report of the commission on ending childhood obesity; 2016 [cited 2017 September 4]. Available from: http://apps.who.int/iris/bitstream/10665/204176/1/9789241510066_eng.pdf. 
36. Joensuu J, Koskenniemi E, Hulkko T, et al. Vaccination coverage among Finnish infants less than 3 years of age - a population-based survey. Finn Med J. 2005;60:3359-3362.

37. National Institute for Health and Welfare. Statistical information on welfare and health in Finland. [cited 2017 September 4] Available from: https://www.sotkanet.fi/sotkanet/en/index

38. Sjöström O, Holst D. Validity of a questionnaire survey: response patterns in different subgroups and the effect of social desirability. Acta Odont Scand. 2002;60(3):136-140.

39. Hebert JR, Ma Y, Clemow L, et al. Gender differences in social desirability and social approval bias in dietary self-report. Am J Epidemiol. 1997;146(12):1046-1055.

40. Durant LE, Carey MP, Schroder KE. Effects of anonymity, gender, and erotophilia on the quality of data obtained from self-reports of socially sensitive behaviors. J Behav Med. 2002;25(5):438-467.

41. Källestål C, Wall S. Socio-economic effect on caries. Incidence data among Swedish 1214-year-olds. Community Dent Oral Epidemiol. 2002;30(2):108-114. 
Table 1. Description of the mothers $(n=179)$ attending well-baby clinics with their child aged 124 months.

\begin{tabular}{|c|c|c|}
\hline $\begin{array}{l}\text { Characteristics and } \\
\text { behaviours }\end{array}$ & $\bar{n}$ & $\%$ \\
\hline \multicolumn{3}{|l|}{ Age (years) } \\
\hline$<25$ & 25 & 14 \\
\hline $25-29$ & 54 & 30 \\
\hline $30-34$ & 59 & 33 \\
\hline $35+$ & 40 & 22 \\
\hline \multicolumn{3}{|l|}{ Missing data $(\mathrm{n}=1)$} \\
\hline \multicolumn{3}{|l|}{ Education attained } \\
\hline Basic & 19 & 11 \\
\hline Middle & 89 & 51 \\
\hline Higher & 67 & 38 \\
\hline \multicolumn{3}{|l|}{ Missing data $(n=4)$} \\
\hline \multicolumn{3}{|l|}{ Smoking habit } \\
\hline Never & 142 & 79 \\
\hline Occasionally & 10 & 6 \\
\hline Regularly & 27 & 15 \\
\hline \multicolumn{3}{|l|}{ Tooth brushing frequency } \\
\hline Twice daily & 127 & 71 \\
\hline Once a day & 47 & 26 \\
\hline Less than daily & 5 & 3 \\
\hline \multicolumn{3}{|l|}{ Consumption of sweets } \\
\hline No more than once a week & 50 & 29 \\
\hline 2-3 times a week & 88 & 50 \\
\hline More frequently & 37 & 21 \\
\hline Missing data $(n=4)$ & & \\
\hline
\end{tabular}


Table 2. Distributions (\%) of 1-24 month-old Finnish children $(\mathrm{N}=179)$ according to their frequency of health-related behaviors; p-values refer to the differences by age.

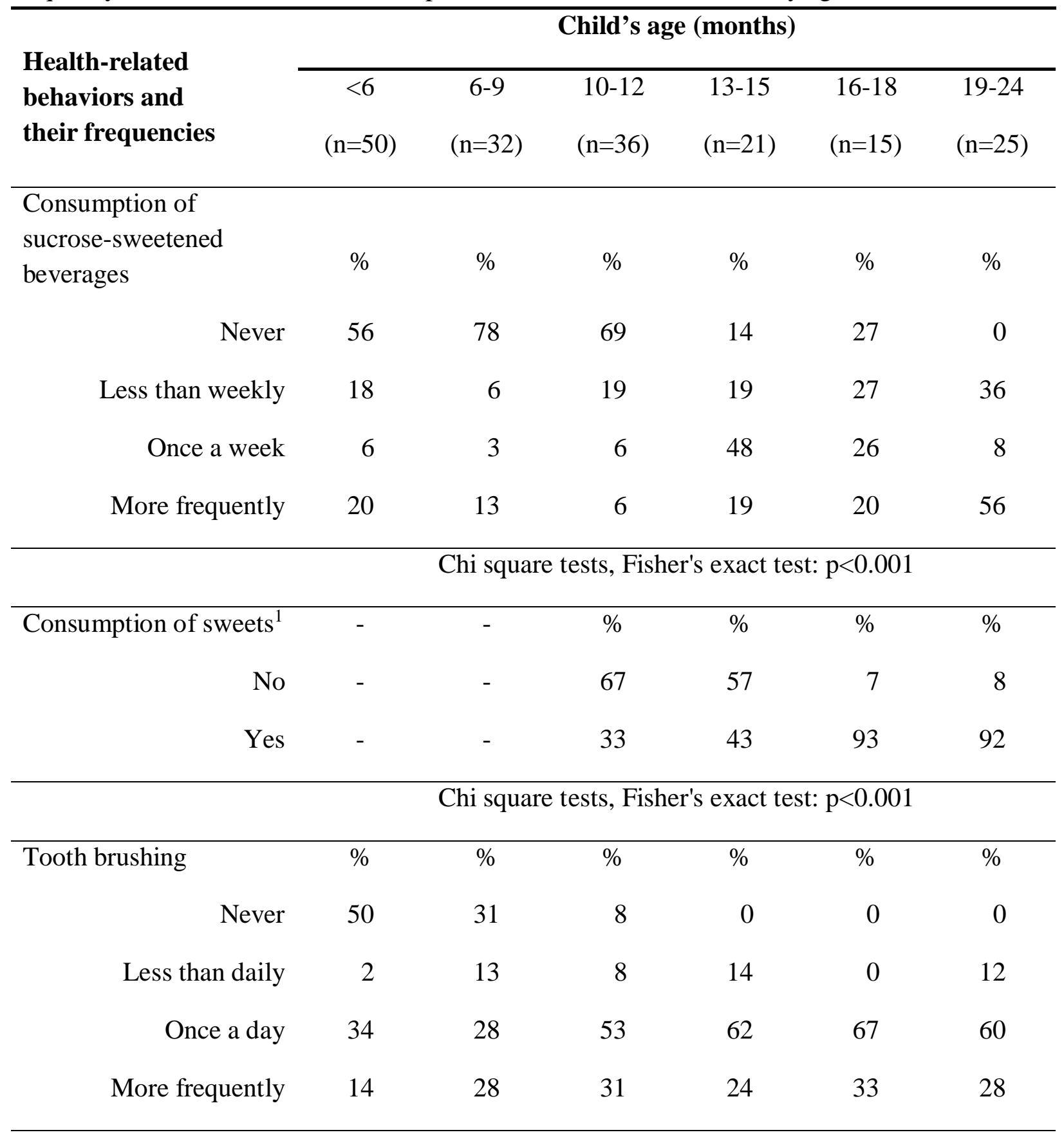

Chi square tests, Fisher's exact test: $p<0.001$

${ }^{1}$ The mothers of infants $<10$ months did not answer the question comprehensively and the question was excluded from the analyses. 


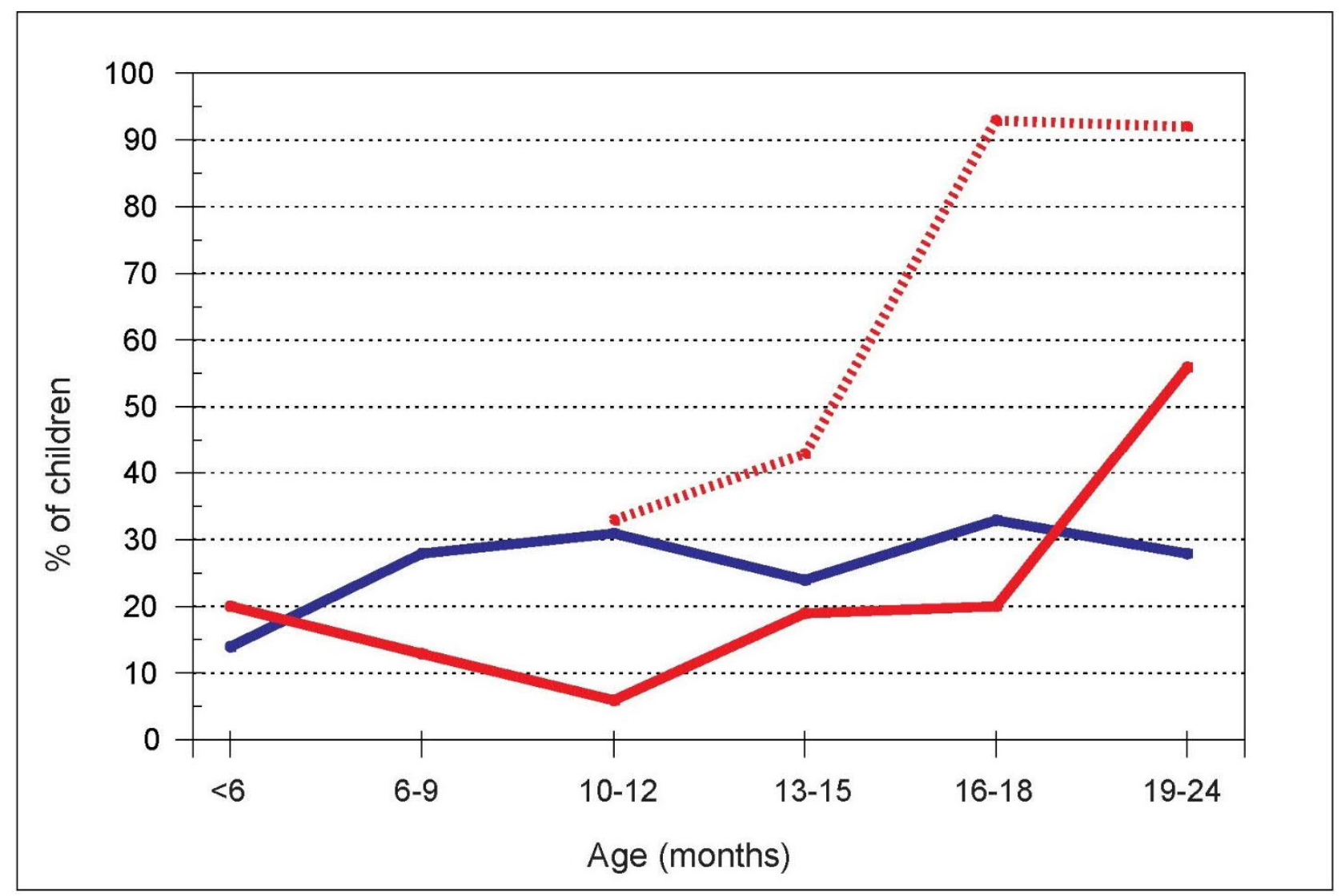

Figure 1. Behaviors reported by mothers for their 1-24-month-old children $(\mathrm{N}=179)$; blue solid line $=$ tooth brushing on twice a day basis; red solid line $=$ sucrose-sweetened beverages more than once a week; red dashed line = any consumption of sweets. 


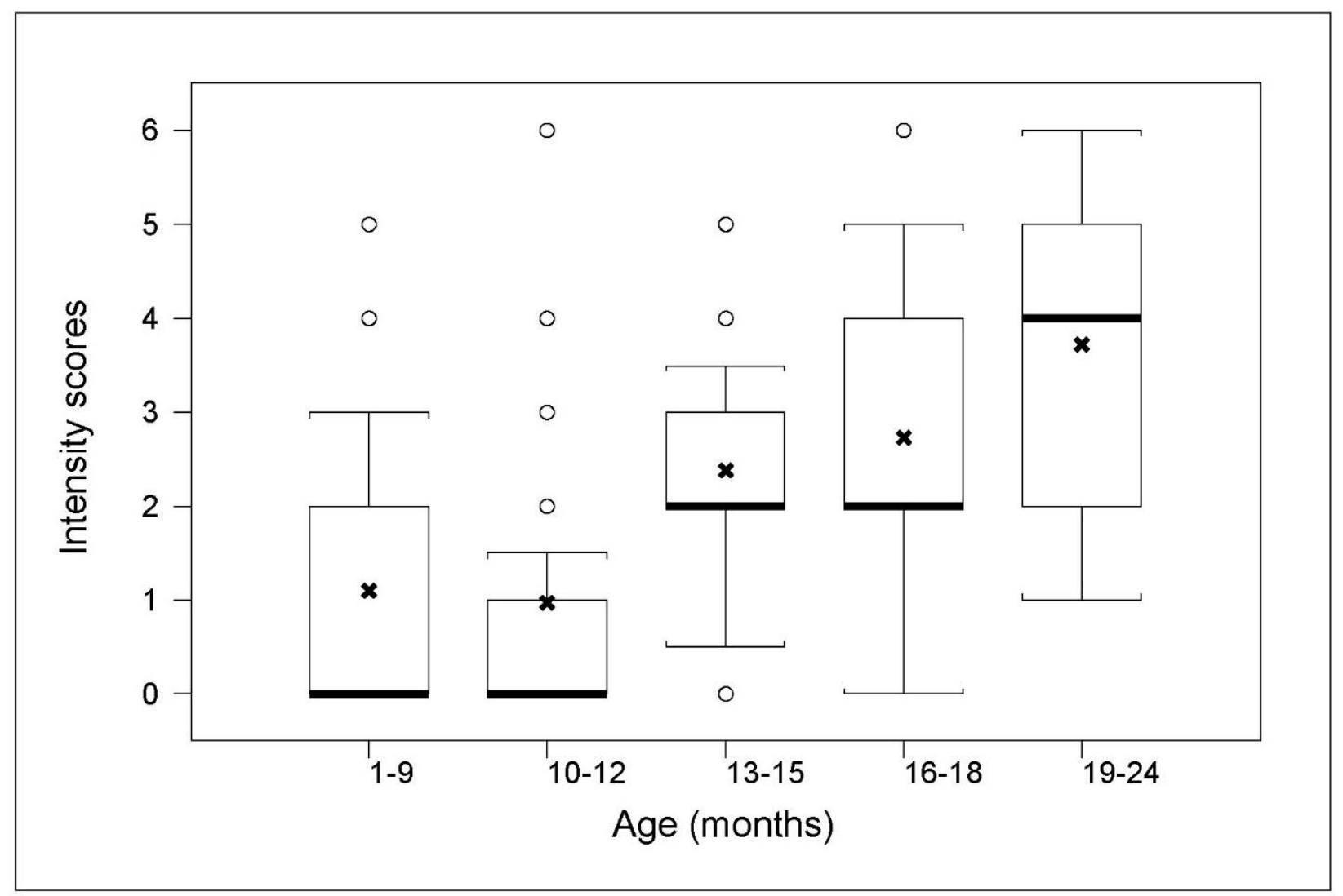

Figure 2. Distributions of the scores describing the intensity of consumption of sucrose-sweetened products (beverages and sweets) by 1-24-month-old children ( $\mathrm{N}=179)$ as reported by their mothers. Intensity scores are sums of the original scores where greater values indicate more frequent use of sucrose-sweetened products. In the box-and-whisker diagram Boxes $=$ Quartiles, Bold line $=$ Median, $\mathrm{X}=$ Mean, Circle $=$ Outlier. 